\title{
Cardiorenal Syndrome Type 4-Cardiovascular Disease in Patients with Chronic Kidney Disease: Epidemiology, Pathogenesis, and Management
}

\author{
Panagiotis Pateinakis and Aikaterini Papagianni \\ Department of Nephrology, Aristotle University of Thessaloniki, General Hospital of Thessaloniki "Hippokration”, Papanastasiou 50, \\ 54642 Thessaloniki, Greece \\ Correspondence should be addressed to Aikaterini Papagianni, aikpapag@otenet.gr
}

Received 30 August 2010; Accepted 3 January 2011

Academic Editor: Claudio Ronco

Copyright (C 2011 P. Pateinakis and A. Papagianni. This is an open access article distributed under the Creative Commons Attribution License, which permits unrestricted use, distribution, and reproduction in any medium, provided the original work is properly cited.

\begin{abstract}
The term cardiorenal syndrome refers to the interaction between the heart and the kidney in disease and encompasses five distinct types according to the initial site affected and the acute or chronic nature of the injury. Type 4, or chronic renocardiac syndrome, involves the features of chronic renal disease (CKD) leading to cardiovascular injury. There is sufficient epidemiologic evidence linking CKD with increased cardiovascular morbidity and mortality. The underlying pathophysiology goes beyond the highly prevalent traditional cardiovascular risk burden affecting renal patients. It involves CKD-related factors, which lead to cardiac and vascular pathology, mainly left ventricular hypertrophy, myocardial fibrosis, and vascular calcification. Risk management should consider both traditional and CKD-related factors, while therapeutic interventions, apart from appearing underutilized, still await further confirmation from large trials.
\end{abstract}

\section{Introduction}

The term cardiorenal syndrome has been introduced recently in an attempt to emphasize the tight interaction between the cardiovascular and renal systems in acute or chronic disease settings and to expand our knowledge regarding its pathogenesis, prevention, and potential treatment [1].

The definition encompasses different syndromes, all involving the heart and the kidney, "whereby acute or chronic dysfunction of one organ may induce an acute or chronic dysfunction of the other" [2]. According to the site of the initial injury and the acute or chronic nature of the process five distinct syndromes (types) are defined. In acute cardio-renal syndrome (Type 1), acute worsening of heart function leads to acute renal dysfunction. In chronic cardiorenal syndrome (Type 2), chronic cardiac dysfunction leads to chronic renal dysfunction. In acute renocardiac syndrome (Type 3), acute renal dysfunction causes cardiac dysfunction, and in chronic renocardiac syndrome (Type 4), chronic renal dysfunction leads to cardiovascular disease and increased cardiovascular mortality [1]. Finally, type 5 , or secondary cardiorenal syndrome, involves systemic conditions such as diabetes mellitus, amyloidosis, systemic lupus erythematosus, or sepsis, which simultaneously affect both the heart and the kidney [2].

This paper will focus on cardiorenal syndrome type 4 (chronic renocardiac syndrome) presenting epidemiologic evidence of excess cardiovascular morbidity and mortality in patients with chronic kidney disease (CKD) as well as current knowledge on the pathogenesis and management of this syndrome.

\section{Epidemiologic Evidence Linking CKD and Cardiovascular Disease (CVD)}

$\mathrm{CKD}$ is defined as either a reduction in the glomerular filtration rate (GFR) to values below $60 \mathrm{ml} / \mathrm{min} / 1.73 \mathrm{~m}^{2}$, or the presence of kidney damage as reflected in an abnormal urine sediment (proteinuria, hematuria, and casts) or 
abnormalities in renal architecture (e.g., polycystic kidney disease) even if the GFR is preserved within normal levels. GFR may be directly measured by renal clearance of specific substances (e.g., creatinine, inulin) and radioactive markers (e.g., 99mTc-DTPA) or it may be estimated (estimated GFReGFR), by the application of formulas incorporating serum creatinine and demographic parameters (Cockcroft-Gault, MDRD) [3].

Both proteinuria and the reduction of GFR have been associated with increased cardiovascular morbidity and mortality [4]. This association is so strong and clinically relevant that according to current guidelines the diagnosis of CKD places a patient into the highest cardiovascular risk level, irrespective of stratification according to traditional cardiovascular risk factors $[3,4]$. Compared to the general population, CKD patients are still plagued by a frustratingly high mortality, which is mainly attributed to cardiovascular events, with death being far more probable than advancing into the final CKD stages and the need of renal replacement therapy (RRT) [5]. The high mortality afflicting patients on renal RRT, which for the ages between 25 and 35 may rise up to 375 -fold compared to the general population [6], is derived almost by half of cardiovascular causes [7].

\subsection{Proteinuria/Albuminuria and CVD. The abnormal} quantities of protein in the urine (proteinuria) consist mainly of albumin (albuminuria) and can be semiquantitatively identified by urine dipstick testing, estimated by the urine protein-to-creatinine ratio (UPCR) or albuminto-creatinine ratio (UACR) in a spot urine sample, or directly measured in a timed (usually $24 \mathrm{~h}$ ) urine collection $[3,8]$. The diagnosis of microalbuminuria (30$300 \mathrm{mg} /$ day) and albuminuria (>300 mg/day) is mainly utilized in the evaluation of diabetic nephropathy, while proteinuria $(>300 \mathrm{mg} /$ day or UPCR $>200 \mathrm{mg} / \mathrm{g})$ is mostly used for nondiabetic CKD [8].

Whether considered a marker of systemic endothelial dysfunction or a result of renal damage [9], proteinuria has been associated with increased cardiovascular mortality in the general population, even at levels regarded as normal [10]. In repeated studies, the presence of micro- and macroalbuminuria and eGFR reduction were independent predictors of increased overall and cardiovascular mortality in diabetic [11] and nondiabetic individuals [12]. In a recently published large community-based study involving nearly one million adult subjects, the presence of proteinuria was assessed by urine dipstick or UACR. Higher levels of proteinuria were independently associated with an increased risk of myocardial infarction and all-cause mortality, as were decreased levels of eGFR. The severity of proteinuria was actually a stronger predictor of worse clinical outcomes than was eGFR reduction, a fact suggesting that levels of proteinuria may have a role in risk stratification of CKD patients, who are currently staged only according to their level of GFR [13].

2.2. GFR and CVD. Irrespective of the presence of proteinuria, GFR decline has been repeatedly associated with increased cardiovascular morbidity and mortality. In a large community study involving more than one million adults, an independent and graded association was observed between eGFR reduction and increased risk of death and cardiovascular events including hospitalization for coronary artery disease, heart failure, stroke, and peripheral vascular disease [14]. In middle-aged adults participating in the Atherosclerosis Risk in Community (ARIC) study, a baseline eGFR of less than $60 \mathrm{ml} / \mathrm{min} / 1.73 \mathrm{~m}^{2}$ was independently associated with an increased risk of developing peripheral arterial disease [15] or heart failure, irrespective of prevalent coronary artery disease [16]. According to United States Renal Data System 2007 annual report regarding incident dialysis patients, comorbidities included congestive heart failure in $34 \%$, atherosclerotic heart disease in $22.5 \%$, cerebrovascular disease in $10 \%$, and peripheral vascular disease in $15 \%$ of cases [17].

2.3. Cardiovascular Outcomes in CKD. In patients with already established cardiovascular disease, renal impairment markedly worsens outcomes. An inverse relationship between eGFR and the extent of coronary stenotic lesions was shown [18], as well as increased probability of having three-vessel coronary artery disease with decreasing eGFR [19]. In a study of almost 15.000 patients, who had suffered myocardial infarction, even mild eGFR reduction at baseline was independently associated with increased overall mortality or a composite end point of death from cardiovascular causes, reinfarction, congestive heart failure, stroke, or resuscitation after cardiac arrest [20]. In patients undergoing coronary artery bypass grafting, a reduced baseline eGFR has also been associated with increased 30-day and long-term mortality [21]. Furthermore, in patients with advanced congestive heart failure, impaired renal function seems to be a stronger predictor of mortality than impaired cardiac function (left ventricular ejection fraction and New York Heart Association class) [22]. Finally, in a recent study also involving patients with heart failure, the presence of albuminuria significantly aggravated prognosis by exhibiting a strong and independent association with increased allcause and cardiovascular mortality [23].

\section{Cardiovascular Injury in CKD}

Due to the vital importance for the rapidly growing population of CKD patients, the pathogenetic mechanisms leading to cardiovascular damage in renal disease are under constant investigation. More than a dozen of pathways have been identified including hyperactivity of the reninangiotensin-aldosterone system, osmotic sodium retention, volume overload, endothelial dysfunction, dyslipidemia, coagulopathy, inflammation, and anemia [24], all leading to histomorphological alterations of the heart and vessels.

In addition, some key emerging topics in this field include sympathetic hyperactivity, cardiotonic steroids, nonosmotic sodium retention, and catalytic or labile iron. Sympathetic activation by the failing kidney leading to both renal disease progression and cardiovascular morbidity 


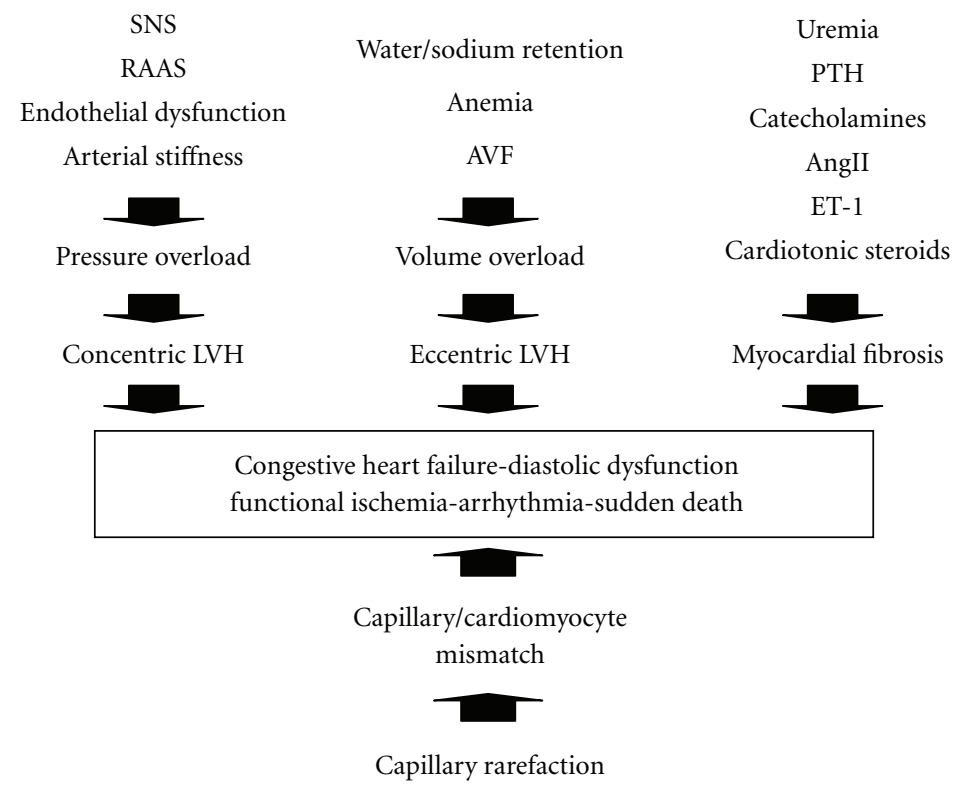

FIgURE 1: Heart alterations and their consequences in CKD. AVF: arteriovenous fistula, AngII: angiotensin II, ET-1: endothelin-1, LVH: left ventricular hypertrophy, PTH: parathormone, RAAS: renin-angiotensin-aldosterone system, SNS: sympathetic nervous system.

and mortality may provide a new target for therapeutic intervention [25]. Cardiotonic steroids are elevated in renal failure and have been linked to hypertension and to the development of uremic cardiomyopathy in animal models [26]. Nonosmotic sodium stores in the form of waterfree $\mathrm{Na}+$ accumulation in the skin have been proposed to contribute to the development of hypertension and thus might be associated to CKD progression and cardiovascular complications [27]. Finally, labile/catalytic iron is associated with oxidative stress in situations such as acute kidney injury after cardiac revascularisation and in diseases such as diabetes and may result in both kidney disease progression and cardiovascular complications [28]. However, an extensive analysis of all the above mechanisms lies outside the scopus of the present paper, and readers are referred to some excellent recent reviews [25-28].

3.1. The Heart in CKD. The mechanisms leading to cardiac alterations in CKD are depicted in Figure 1. Cardiac workload is increased in CKD. This increase is the result of two separate pathways both leading to left ventricular hypertrophy $(\mathrm{LVH})$ : pressure overload and volume overload. Pressure overload mainly derives from increased peripheral resistance and reduced arterial compliance due to sympathetic and renin-angiotensin system hyperactivity, hypertension, endothelial dysfunction, and vascular calcification/stiffening. It causes thickening of cardiac myofibres by parallel addition of sarcomeres, thus leading to concentric LVH. Volume overload is attributed to sodium and water retention, anemia, and the presence of an arteriovenous fistula in patients with endstage renal disease (eGFR $<15 \mathrm{ml} / \mathrm{min} / 1.73 \mathrm{~m}^{2}$ anticipating or on chronic dialysis). It results in lengthening of the cardiac myofibers by serial addition of sarcomeres thus causing eccentric LVH (left ventricular dilatation) $[29,30]$. LVH in renal disease is a pathologic process and, unlike physiologic adaptations to increased workload (e.g., "athletes heart"), is accompanied by fibrosis, which is also attributed to conditions related to the uremic milieu, including increased levels of parathyroid hormone, endothelin, aldosterone, catecholamines, and cardiotonic steroids [26, 30, 31]. In a study involving 432 ESRD patients, only $16 \%$ had a normal echocardiogram at initiation of dialysis, the rest exhibiting mainly features of concentric LVH (41\%) and left ventricular dilatation $(28 \%)$, both associated with increased risk of heart failure and death [32]. A more recent study demonstrated progression of concentric LVH in 576 new dialysis patients followed up by echocardiography [33].

In addition to fibrosis and cardiomyocyte hypertrophy, histological changes of the heart in uremia also include myocyte apoptosis/necrosis resulting in myocyte number reduction, and microvascular abnormalities such as arteriolar wall thickening and capillary rarefaction, the latter being specific to uremia $[29,34]$.

The functional consequences of all the aforementioned structural changes include diastolic dysfunction [35], increased oxygen demand and impaired, myocardial oxygenation unrelated to coronary obstruction $[34,36]$. This may explain the angiographic finding of patent coronaries in $30 \%-40 \%$ of uremic patients with ischemic heart disease/angina pectoris [34], as well as their predisposition to arrhythmias, both atrial and ventricular, and sudden death, which account for more than half of the cardiovascular mortality of patients on RRT $[37,38]$. Susceptibility to arrhythmias and sudden death may be further increased by coronary artery disease/myocardial infarction, left ventricular hypertrophy, congestive heart failure, electrolyte abnormalities, chronic fluid overload, anemia, autonomic imbalance, and inflammation [38]. 
3.2. Vascular Changes in CKD. Ever since early reports of aortic thickening in uremic patients by Richard Bright in 1827, renal disease has been associated with vascular pathology [39]. Pathologic features include reduced elasticity/compliance of large arteries, as reflected in an increase of the arterial pulse wave velocity (PWV) [40, 41], thickening of the arterial wall, leading to an increased intima-media thickness (IMT) [42], and, mainly, vascular calcification $[43,44]$.

Vascular calcification has recently been the focus of attention mainly because of its established association with cardiovascular mortality in CKD patients [45]. Moreover, in the last decade, research has shown that it is not simply the result of passive mineral precipitation but rather an active and highly regulated process, closely resembling osteogenesis $[43,46]$, and is orchestrated by the arterial smooth muscle cell after its genotypic transformation to an osteoblast-like cell [43]. Ossification of the arterial wall is favoured by conditions like ageing, diabetes, inflammation, and especially CKD. In renal disease, vascular calcification is linked to hyperphosphatemia, lack of calcification inhibitors (i.e., fetuin-A, matrix GLa protein, osteopontin, or pyrophosphate) and derangements in regulators of mineral metabolism (i.e., vitamin D, parathormone, osteoprotegerin, and bone morphogenetic proteins) [43], and abnormalities in bone turnover such as secondary hyperparathyroidism and adynamic bone disease [46-48].

In addition, recent studies implied a role for the phosphatonin Fibroblast Growth Factor-23 (FGF-23) in the pathophysiology of chronic kidney disease-mineral bone disorder (CKD-CMD) and in vascular calcification. FGF23 levels are elevated in CKD patients both on dialysis and on conservative treatment and have been associated with increased mortality and left ventricular hypertrophy. Moreover, FGF-23 has been linked to increased arterial stiffness, endothelial dysfunction, and vascular calcification. However, a causative relation and its value as a marker of cardiovascular status and/or phosphate-related toxicity, as well as its potential role as a target for intervention, still await further clarification [49].

Calcium deposits may surround atheromatous plaques in the arterial intima (atherosclerosis) or involve the medial layer of the arteries (arteriosclerosis-Moenckeberg's sclerosis) [50]. They can be visualised in plain X-ray films $[51,52]$ and quantified by more sophisticated and more expensive techniques like electron beam computed tomography $(\mathrm{EBCT})[53,54]$, the latter regarding mainly coronary artery calcification (CAC).

Whether vascular intima and media calcification are really distinct entities still remains controversial. Because of the results from experimental models as well as their difference in histopathologic features, location in the arterial tree, and pathophysiologic consequences, they tend to be regarded as distinct [50] although this view has recently been challenged $[55,56]$. Both types of vascular calcification appear early in CKD, run an accelerated course, especially after RRT initiation $[53,54]$, and lead to high cardiovascular morbidity and mortality [45]. More importantly, a recent metareview on treatments for vascular calcification in CKD has demonstrated that no therapy to date, including statins and sevelamer, appears to influence their rate of progression [57].

In CKD patients, CAC score measurement as a tool for cardiovascular risk stratification may be affected by the unique presence of medial coronary calcification [58, 59] unrelated to obstructive coronary atherosclerosis, thus not necessarily leading to ischemia. Nevertheless, a high CAC score has been associated with increased mortality in CKD patients both before [60] and after the initiation of dialysis [61]. Apart from medial calcification, another feature characteristic of coronary artery disease (CAD) affecting CKD patients is the location of culprit atherosclerotic lesions. In renal patients with acute myocardial infarction, they were found to be located more proximal to the coronary ostia, which may account for the observed increased mortality [62].

Because CAD is highly prevalent in CKD patients, noninvasive screening tools for the prediction of asymptomatic coronary obstruction are needed. In recent studies, cardiac Troponin $\mathrm{T}$ (cTnT) has emerged as a powerful predictor of multiple-vessel CAD in asymptomatic hemodialysis patients $[63,64]$. In addition, the acute kidney injury biomarker neutrophil gelatinase-associated lipocalin (NGAL) has recently been associated with both chronic renal impairment and cardiovascular complications and might potentially prove its worth as a cardiovascular risk predictor in CKD [65].

Aortic calcification assessed by lateral abdominal X-ray has also been associated with all-cause and cardiovascular mortality in dialysis patients and has been proposed as a simple tool for cardiovascular risk assessment and treatment guidance $[52,66]$.

\section{Cardiovascular Risk Modification in CKD}

Because of the heavy CVD burden affecting CKD patients, risk modification is vital in an effort to improve outcomes. Still CKD patients are usually excluded from large interventional trials [67] because of their expected adverse outcomes, thus hindering the evaluation of therapeutic interventions. Furthermore, interventions for traditional cardiovascular risk reduction already established in the general population have proved less effective in patients with CKD [24, 68, 69]. This seems to result into a kind of "therapeutic nihilism" [24], by denying treatment despite the presence of sound indications, for example, the underutilisation of antiplatelets, statins, $\beta$ blockers, and ACE inhibitors in CKD patients with known CAD [70]. Furthermore, CKD patients are less likely to undergo coronary angiography, percutaneous coronary intervention, or bypass grafting, or to receive adjuvant treatments, such as GpIIb/IIIa inhibitors [67].

Strategies to reduce cardiovascular risk in CKD patients should target both traditional and non-traditional, that is, CKD-related factors. Traditional risk factors include hypertension, dyslipidemia, diabetes, obesity, physical activity, and smoking habit, while CKD-related factors refer to CKD progression, proteinuria, anemia, inflammation, mineral and bone disorder, LVH, oxidative stress, coagulopathy, 
hyperactivity of the renin-angiotensin and the sympathetic nervous system, and dialysis dose and quality [67] (Table 1).

Setting of specific treatment targets is complicated, especially in patients on RRT, by findings of reverse epidemiology with a U-shaped curve associating mortality with blood pressure, BMI, cholesterol, and phosphate [71], possibly a result of the Malnutrition-Inflammation-Atherosclerosis (MIA) syndrome frequently encountered in this patient population $[72,73]$. Further controversies also derive from recent results of increased morbidity and mortality in CKD patients associated with higher hemoglobin levels [74], intensive blood pressure [75] and glucose control [76], dual angiotensin II blockade [77] and suppression of parathyroid function, and bone turnover $[47,48]$, which question the safety of overaggressive intervention on specific laboratory and clinical parameters in this patient group. Rather than meticulously pursuing generalised targets, recent opinions suggest a potential benefit from a more individualised perspective, that takes into account patient-specific trends and distinctive dynamic features of the actual clinical situation $[66,78,79]$.

Eagerly awaited is the publication of results from large randomised studies evaluating therapeutic interventions to lower cardiovascular morbidity and mortality in CKD patients, such as the ongoing EVOLVE (EValuation Of Cinacalcet $\mathrm{HCl}$ Therapy to Lower CardioVascular Events) [80] and the concluded SHARP (Study in Heart And Renal Protection). The latter, a double blind placebo-controlled study involving almost 9500 CKD patients (a third of them on dialysis) in 18 countries, has been able to demonstrate a significant reduction in cardiovascular events, such as myocardial infarction, stroke, or need for coronary artery revascularization, with the use of a combination of ezetimibe plus simvastatin, according to most recent results presented during the American Society of Nephrology Renal Week 2010 [81].

Until further results are available, current recommendation for predialysis patients suggests regular exercise, where feasible, smoking cessation, blood pressure control to $<130 / 80 \mathrm{mmHg}$ with preference to angiotensin-II-targeted treatment, $\mathrm{HbAl}_{c}$ levels of $<7.0 \%$, Hb levels of $10-12 \mathrm{~g} / \mathrm{dL}$, LDL cholesterol levels as for the general population with high cardiovascular risk, sodium intake $<2.4 \mathrm{~g} /$ day, maintenance of a BMI $<25 \mathrm{~kg} / \mathrm{m}^{2}$, treatment of proteinuria, and avoidance of nephrotoxicity, aiming, apart from cardiovascular protection, at renal function preservation and slowing of CKD progression [3, 67, 82-84].

For patients on dialysis, blood pressure of $<140 /$ $90 \mathrm{mmHg}$ before and $<130 / 80 \mathrm{mmHg}$ after dialysis is recommended. Optimal levels of HbA1c and LDL-C seem to be less clearly defined, since they may not accurately reflect glycemic status [85] and atherogenic potential [86], mainly because of the short erythrocyte lifespan [85] and the qualitative rather than quantitative lipid abnormalities in uremia [86]. Special consideration must be taken to mineral bone disorder aiming at normal phosphorus levels, avoiding hypercalcemia, and treating secondary hyperparathyroidism judiciously in order to maintain the mineral buffering ability of active bone turnover, in order to ameliorate vascular calcification [66].
TABLE 1: Targets for cardiovascular risk modification in CKD.

\begin{tabular}{ll}
\hline Traditional & CKD related \\
\hline Physical activity & Proteinuria \\
Smoking & CKD progression \\
Obesity & Sympathetic nervous system \\
Blood pressure & Renin-angiotensin system \\
Glycemia & Left ventricular hypertrophy \\
Lipids & Mineral bone disorder \\
& Anaemia \\
& Inflammation \\
& Oxidative stress \\
& Coagulopathy \\
& Dialysis dose and quality \\
\hline
\end{tabular}

The latter is portrayed in recent recommendations regarding vascular calcification screening, phosphate binder choice, and target levels of parathormone [66, 87, 88]. Also of importance are dialysis adequacy, quality, and hemodynamic stability, as well as the optimization of conditions regarding inflammation and dialysis-related infections $[89,90]$.

The treatment and prevention of arrhythmias and sudden death remains a challenge. Apart from attention to electrolyte disorders and avoidance of low-potassium dialysate, whenever possible, the use of $\beta$ blockers seems beneficial. ACE inhibitors and angiotensin II receptor blockers appear promising but have yet to prove their efficacy in prospective trials [38]. Implantation of cardiac defibrillators in dialysis patients is associated with increased risk for bleeding and infection. Compared to patients with normal renal function, their use for primary prevention in CKD patients confers a reduced survival benefit, possibly due to comorbid conditions or increased defibrillation thresholds. On the other hand, implantation for secondary prevention is underused in dialysis patients, despite a proven effect in reducing mortality $[37,38]$.

In summary, CKD patients carry a heavy cardiovascular burden leading to high morbidity and mortality. This can be attributed to the high prevalence of traditional risk factors, such as advanced age, diabetes, and hypertension but also derives from CKD-related morbidity, such as sympathetic and renin-angiotensin hyperactivity, sodium retention, fluid overload, anemia, dyslipidemia, mineral-bone disorder and inflammation, which lead to structural alterations of the heart and vessels (chronic renocardiac syndrome). Aggressive risk modification, high index of suspicion for cardiovascular morbidity, proper intervention, and secondary prevention are essential. Large high-quality trials involving CKD patients are urgently needed to provide results, which could support effective treatment strategies. Until such results are available, avoiding "therapeutic nihilism" and aiming at established treatment targets with an individualised patientoriented approach appears sensible. 


\section{References}

[1] C. Ronco, P. McCullough, S. D. Anker et al., "Cardio-renal syndromes: report from the consensus conference of the acute dialysis quality initiative," European Heart Journal, vol. 31, no. 6, pp. 703-711, 2010.

[2] A. A. House, I. Anand, R. Bellomo et al., "Definition and classification of Cardio-Renal Syndromes: workgroup statements from the 7th ADQI Consensus Conference," Nephrology Dialysis Transplantation, vol. 25, no. 5, pp. 1416-1420, 2010.

[3] National Kidney Foundation, "KDQI clinical practice guidelines for chronic kidney disease: evaluation, classification and stratification," American Journal of Kidney Diseases, vol. 39, no. 2, supplement 1, pp. S1-S266, 2002.

[4] M. Tonelli, N. Wiebe, B. Culleton et al., "Chronic kidney disease and mortality risk: a systematic review," Journal of the American Society of Nephrology, vol. 17, no. 7, pp. 2034-2047, 2006.

[5] D. S. Keith, G. A. Nichols, C. M. Gullion, J. B. Brown, and D. H. Smith, "Longitudinal follow-up and outcomes among a population with chronic kidney disease in a large managed care organization," Archives of Internal Medicine, vol. 164, no. 6, pp. 659-663, 2004.

[6] R. Vanholder, Z. Massy, A. Argiles et al., "Chronic kidney disease as cause of cardiovascular morbidity and mortality," Nephrology Dialysis Transplantation, vol. 20, no. 6, pp. 10481056, 2005.

[7] US Renal Data System: USRDS 2009 Annual Data Report: Reference Tables, "Patient characteristics Bethesda, National Institutes of Health, National Institute of Diabetes and Digestive and Kidney Diseases," 2009, http://www.usrds.org/2009/pdf/V2_06_09.PDF.

[8] N. J. McIntyre and M. W. Taal, "How to measure proteinuria?" Current Opinion in Nephrology and Hypertension, vol. 17, no. 6, pp. 600-603, 2008.

[9] C. D. A. Stehouwer and Y. M. Smulders, "Microalbuminuria and risk for cardiovascular disease: analysis of potential mechanisms," Journal of the American Society of Nephrology, vol. 17, no. 8, pp. 2106-2111, 2006.

[10] H. L. Hillege, V. Fidler, G. F. H. Diercks et al., "Urinary albumin excretion predicts cardiovascular and noncardiovascular mortality in general population," Circulation, vol. 106, no. 14, pp. 1777-1782, 2002.

[11] T. Ninomiya, V. Perkovic, B. E. De Galan et al., "Albuminuria and kidney function independently predict cardiovascular and renal outcomes in diabetes," Journal of the American Society of Nephrology, vol. 20, no. 8, pp. 1813-1821, 2009.

[12] B. C. Astor, S. I. Hallan, E. R. Miller, E. Yeung, and J. Coresh, "Glomerular filtration rate, albuminuria, and risk of cardiovascular and all-cause mortality in the US population," American Journal of Epidemiology, vol. 167, no. 10, pp. 12261234, 2008.

[13] B. R. Hemmelgarn, B. J. Manns, A. Lloyd et al., "Relation between kidney function, proteinuria, and adverse outcomes," Journal of the American Medical Association, vol. 303, no. 5, pp. 423-429, 2010.

[14] A. S. Go, G. M. Chertow, D. Fan, C. E. McCulloch, and C. Y. Hsu, "Chronic kidney disease and the risks of death, cardiovascular events, and hospitalization," New England Journal of Medicine, vol. 351, no. 13, pp. 1296-1305, 2004.

[15] K. Wattanakit, A. R. Folsom, E. Selvin, J. Coresh, A. T. Hirsch, and B. D. Weatherley, "Kidney function and risk of peripheral arterial disease: results from the Atherosclerosis
Risk in Communities (ARIC) study," Journal of the American Society of Nephrology, vol. 18, no. 2, pp. 629-636, 2007.

[16] A. Kottgen, S. D. Russell, L. R. Loehr et al., "Reduced kidney function as a risk factor for incident heart failure: the Atherosclerosis Risk in Communities (ARIC) study," Journal of the American Society of Nephrology, vol. 18, no. 4, pp. 13071315, 2007.

[17] US Renal Data System: USRDS 2007 Annual Data Report: Reference Tables, "Patient characteristics Bethesda, National Institutes of Health, National Institute of Diabetes and Digestive and Kidney Diseases, 2007," August 2010, http://www.usrds.org/2009/ref/C_Ref_09.pdf.

[18] D. Weber-Mzell, P. Kotanko, M. Schumacher, W. Klein, and F. Skrabal, "Coronary anatomy predicts presence or absence of renal artery stenosis: a prospective study in patients undergoing cardiac catheterization for suspected coronary artery disease," European Heart Journal, vol. 23, no. 21, pp. 1684-1691, 2002.

[19] C. M. Gibson, R. L. Dumaine, E. V. Gelfand et al., "Association of glomerular filtration rate on presentation with subsequent mortality in non-ST-segment elevation acute coronary syndrome; observations in 13307 patients in five TIMI trials," European Heart Journal, vol. 25, no. 22, pp. 1998-2005, 2004.

[20] N. S. Anavekar, J. J. V. McMurray, E. J. Velazquez et al., "Relation between renal dysfunction and cardiovascular outcomes after myocardial infarction," New England Journal of Medicine, vol. 351, no. 13, pp. 1285-1295, 2004.

[21] G. S. Hillis, B. L. Croal, K. G. Buchan et al., "Renal function and outcome from coronary artery bypass grafting: impact on mortality after a 2.3-year follow-up," Circulation, vol. 113, no. 8, pp. 1056-1062, 2006.

[22] H. L. Hillege, A. R. J. Girbes, P. J. De Kam et al., "Renal function, neurohormonal activation, and survival in patients with chronic heart failure," Circulation, vol. 102, no. 2, pp. 203-210, 2000.

[23] C. E. Jackson, S. D. Solomon, H. C. Gerstein et al., "Albuminuria in chronic heart failure: prevalence and prognostic importance," The Lancet, vol. 374, no. 9689, pp. 543-550, 2009.

[24] P. A. McCullough, "Why is chronic kidney disease the "spoiler" for cardiovascular outcomes?" Journal of the American College of Cardiology, vol. 41, no. 5, pp. 725-728, 2003.

[25] L. C. Rump, K. Amann, S. Orth, and E. Ritz, "Sympathetic overactivity in renal disease: a window to understand progression and cardiovascular complications of uraemia?" Nephrology Dialysis Transplantation, vol. 15, no. 11, pp. 17351738, 2010.

[26] D. J. Kennedy, S. Vetteth, S. M. Periyasamy et al., "Central role for the cardiotonic steroid marinobufagenin in the pathogenesis of experimental uremic cardiomyopathy," Hypertension, vol. 47, no. 3, pp. 488-495, 2006.

[27] J. Titze, "Water-free sodium accumulation," Seminars in Dialysis, vol. 22, no. 3, pp. 253-255, 2009.

[28] S. Swaminathan and S. V. Shah, "Novel approaches targeted toward oxidative stress for the treatment of chronic kidney disease," Current Opinion in Nephrology and Hypertension, vol. 17, no. 2, pp. 143-148, 2008.

[29] K. Amann, I. Rychlik, G. Miltenberger-Milteny, and E. Ritz, "Left ventricular hypertrophy in renal failure," Kidney International, Supplement, vol. 54, no. 68, pp. S78-S85, 1998.

[30] G. M. London, "Left ventricular alterations and end-stage renal disease," Nephrology Dialysis Transplantation, vol. 17, no. 1, pp. 29-36, 2002. 
[31] K. Amann, C. Wanner, and E. Ritz, "Cross-talk between the kidney and the cardiovascular system," Journal of the American Society of Nephrology, vol. 17, no. 8, pp. 2112-2119, 2006.

[32] P. S. Parfrey, R. N. Foley, J. D. Harnett, G. M. Kent, D. C. Murray, and P. E. Barre, "Outcome and risk factors for left ventricular disorders in chronic uraemia," Nephrology Dialysis Transplantation, vol. 11, no. 7, pp. 1277-1285, 1996.

[33] R. N. Foley, B. M. Curtis, E. W. Randell, and P. S. Parfrey, "Left ventricular hypertrophy in new hemodialysis patients without symptomatic cardiac disease," Clinical Journal of the American Society of Nephrology, vol. 5, no. 5, pp. 805-813, 2010.

[34] K. Amann and E. Ritz, "The heart in renal failure: Morphological changes of the myocardium-new insights," Journal of Clinical and Basic Cardiology, vol. 4, no. 2, pp. 109-113, 2001.

[35] M. A. Losi, B. Memoli, C. Contaldi et al., "Myocardial fibrosis and diastolic dysfunction in patients on chronic haemodialysis," Nephrology Dialysis Transplantation, vol. 25, no. 6, pp. 1950-1954, 2010.

[36] R. J. Middleton, P. S. Parfrey, and R. N. Foley, "Left ventricular hypertrophy in the renal patient," Journal of the American Society of Nephrology, vol. 12, no. 5, pp. 1079-1084, 2001.

[37] P. A. McCullough and K. R. Sandberg, "Chronic kidney disease and sudden death: strategies for prevention," Blood Purification, vol. 22, no. 1, pp. 136-142, 2004.

[38] C. A. Herzog, J. M. Mangrum, and R. Passman, "Sudden cardiac death and dialysis patients," Seminars in Dialysis, vol. 21, no. 4, pp. 300-307, 2008.

[39] L. S. Ibels, A. C. Alfrey, W. E. Huffer, P. W. Craswell, J. T. Anderson, and R. Weil III, "Arterial calcification and pathology in uremic patients undergoing dialysis," American Journal of Medicine, vol. 66, no. 5, pp. 790-796, 1979.

[40] J. Blacher, A. P. Guerin, B. Pannier, S. J. Marchais, M. E. Safar, and G. M. London, "Impact of aortic stiffness on survival in end-stage renal disease," Circulation, vol. 99, no. 18, pp. 2434 2439, 1999.

[41] Y. Ohya, K. Iseki, C. Iseki, T. Miyagi, K. Kinjo, and S. Takishita, "Increased pulse wave velocity is associated with low creatinine clearance and proteinuria in a screened cohort," American Journal of Kidney Diseases, vol. 47, no. 5, pp. 790797, 2006.

[42] U. Schwarz, M. Buzello, E. Ritz et al., "Morphology of coronary atherosclerotic lesions in patients with end-stage renal failure," Nephrology Dialysis Transplantation, vol. 15, no. 2, pp. 218-223, 2000.

[43] M. Mizobuchi, D. Towler, and E. Slatopolsky, "Vascular calcification: the killer of patients with chronic kidney disease," Journal of the American Society of Nephrology, vol. 20, no. 7, pp. 1453-1464, 2009.

[44] P. A. McCullough, M. Agarwal, and V. Agrawal, "Risks of coronary artery calcification in chronic kidney disease: do the same rules apply?" Nephrology, vol. 14, no. 4, pp. 428-436, 2009.

[45] J. Blacher, A. P. Guerin, B. Pannier, S. J. Marchais, and G. M. London, "Arterial calcifications, arterial stiffness, and cardiovascular risk in end-stage renal disease," Hypertension, vol. 38, no. 4, pp. 938-942, 2001.

[46] S. M. Moe and N. X. Chen, "Mechanisms of vascular calcification in chronic kidney disease," Journal of the American Society of Nephrology, vol. 19, no. 2, pp. 213-216, 2008.

[47] G. M. London, S. J. Marchais, A. P. Guérin, P. Boutouyrie, F. Métivier, and M. C. De Vernejoul, "Association of bone activity, calcium load, aortic stiffness, and calcifications in ESRD," Journal of the American Society of Nephrology, vol. 19, no. 9, pp. 1827-1835, 2008.
[48] V. M. Brandenburg and J. Floege, "Adynamic bone diseasebone and beyond," NDT Plus, vol. 1, no. 3, pp. 135-147, 2008.

[49] T. E. Larsson, "The role of FGF-23 in CKD-MBD and cardiovascular disease: friend or foe?" Nephrology Dialysis Transplantation, vol. 25, no. 5, pp. 1376-1381, 2010.

[50] K. Amann, "Media calcification and intima calcification are distinct entities in chronic kidney disease," Clinical Journal of the American Society of Nephrology, vol. 3, no. 6, pp. 15991605, 2008.

[51] T. Adragao, A. Pires, C. Lucas et al., "A simple vascular calcification score predicts cardiovascular risk in haemodialysis patients," Nephrology Dialysis Transplantation, vol. 19, no. 6, pp. 1480-1488, 2004.

[52] S. Okuno, E. Ishimura, K. Kitatani et al., "Presence of abdominal aortic calcification is significantly associated with all-cause and cardiovascular mortality in maintenance hemodialysis patients," American Journal of Kidney Diseases, vol. 49, no. 3, pp. 417-425, 2007.

[53] J. Braun, M. Oldendorf, W. Moshage, R. Heidler, E. Zeitler, and F. C. Luft, "Electron beam computed tomography in the evaluation of cardiac calcifications in chronic dialysis patients," American Journal of Kidney Diseases, vol. 27, no. 3, pp. 394-401, 1996.

[54] W. G. Goodman, J. Goldin, B. D. Kuizon et al., "Coronaryartery calcification in young adults with end-stage renal disease who are undergoing dialysis," New England Journal of Medicine, vol. 342, no. 20, pp. 1478-1483, 2000.

[55] P. A. McCullough, K. M. Chinnaiyan, V. Agrawal, E. Danielewicz, and G. S. Abela, "Amplification of atherosclerotic calcification and Mönckeberg's sclerosis: a spectrum of the same disease process," Advances in Chronic Kidney Disease, vol. 15, no. 4, pp. 396-412, 2008.

[56] P. A. McCullough, V. Agrawal, E. Danielewicz, and G. S. Abela, "Accelerated atherosclerotic calcification and mönckeberg's sclerosis: a continuum of advanced vascular pathology in chronic kidney disease," Clinical Journal of the American Society of Nephrology, vol. 3, no. 6, pp. 1585-1598, 2008.

[57] P. A. McCullough and K. M. Chinnaiyan, "Annual progression of coronary calcification in trials of preventive therapies a systematic review," Archives of Internal Medicine, vol. 169, no. 22, pp. 2064-2070, 2009.

[58] S. Nakamura, H. Ishibashi-Ueda, S. Niizuma, F. Yoshihara, T. Horio, and Y. Kawano, "Coronary calcification in patients with chronic kidney disease and coronary artery disease," Clinical Journal of the American Society of Nephrology, vol. 4, no. 12, pp. 1892-1900, 2009.

[59] A. N. Wade and M. P. Reilly, "Coronary calcification in chronic kidney disease: morphology, mechanisms and mortality," Clinical Journal of the American Society of Nephrology, vol. 4, no. 12, pp. 1883-1885, 2009.

[60] R. Watanabe, M. M. Lemos, S. R. Manfredi, S. A. Draibe, and M. E. F. Canziani, "Impact of cardiovascular calcification in nondialyzed patients after 24 months of follow-up," Clinical Journal of the American Society of Nephrology, vol. 5, no. 2, pp. 189-194, 2010.

[61] G. A. Block, P. Raggi, A. Bellasi, L. Kooienga, and D. M. Spiegel, "Mortality effect of coronary calcification and phosphate binder choice in incident hemodialysis patients," Kidney International, vol. 71, no. 5, pp. 438-441, 2007.

[62] D. M. Charytan, R. E. Kuntz, M. Garshick, S. Candia, M. F. Khan, and L. Mauri, "Location of acute coronary artery thromboses in patients with and without chronic kidney disease," Kidney International, vol. 75, no. 1, pp. 80-87, 2009. 
[63] C. DeFilippi, S. Wasserman, S. Rosanio et al., "Cardiac troponin $\mathrm{T}$ and $\mathrm{C}$-reactive protein for predicting prognosis, coronary atherosclerosis, and cardiomyopathy in patients undergoing long-term hemodialysis," Journal of the American Medical Association, vol. 290, no. 3, pp. 353-359, 2003.

[64] T. Hayashi, Y. Obi, T. Kimura et al., "Cardiac troponin $\mathrm{T}$ predicts occult coronary artery stenosis in patients with chronic kidney disease at the start of renal replacement therapy," Nephrology Dialysis Transplantation, vol. 23, no. 9, pp. 2936-2942, 2008.

[65] D. Bolignano, G. Coppolino, A. Lacquaniti, and M. Buemi, "From kidney to cardiovascular diseases: NGAL as a biomarker beyond the confines of nephrology," European Journal of Clinical Investigation, vol. 40, no. 3, pp. 273-276, 2010.

[66] Kidney Disease Improving Global Outcomes (KDIGO), "Clinical practice guideline for the diagnosis, evaluation, prevention, and treatment of chronic kidney disease-mineral and bone disorder (CKD-MBD). Vascular calcification," Kidney International, vol. 76, supplement 113, pp. S22-S49, 2009.

[67] D. Rucker and M. Tonelli, "Cardiovascular risk and management in chronic kidney disease," Nature Reviews Nephrology, vol. 5, no. 5, pp. 287-296, 2009.

[68] C. Wanner, V. Krane, W. März et al., "Atorvastatin in patients with type 2 diabetes mellitus undergoing hemodialysis," New England Journal of Medicine, vol. 353, no. 3, pp. 238-248, 2005.

[69] B. C. Fellström, A. G. Jardine, R. E. Schmieder et al., "Rosuvastatin and cardiovascular events in patients undergoing hemodialysis," New England Journal of Medicine, vol. 360, no. 14, pp. 1395-1407, 2009.

[70] G. R. Bailie, G. Eisele, L. Liu et al., "Patterns of medication use in the RRI-CKD study: focus on medications with cardiovasculars effects," Nephrology Dialysis Transplantation, vol. 20, no. 6, pp. 1110-1115, 2005.

[71] K. Kalantar-Zadeh, G. Block, M. H. Humphreys, and J. D. Kopple, "Reverse epidemiology of cardiovascular risk factors in maintenance dialysis patients," Kidney International, vol. 63, no. 3, pp. 793-808, 2003.

[72] R. Pecoits-Filho, B. Lindholm, and P. Stenvinkel, "The malnutrition, inflammation, and atherosclerosis (MIA) syndromethe heart of the matter," Nephrology Dialysis Transplantation, vol. 17, supplement 11, pp. 28-31, 2002.

[73] Y. Liu, J. Coresh, J. A. Eustace et al., "Association between cholesterol level and mortality in dialysis patients: role of inflammation and malnutrition," Journal of the American Medical Association, vol. 291, no. 4, pp. 451-459, 2004.

[74] E. F. Unger, A. M. Thompson, M. J. Blank, and R. Temple, "Erythropoiesis-stimulating agents_-time for a reevaluation," New England Journal of Medicine, vol. 362, no. 3, pp. 189-192, 2010.

[75] L. J. Appel, J. T. Wright Jr., T. Greene et al., "Intensive bloodpressure control in hypertensive chronic kidney disease," New England Journal of Medicine, vol. 363, no. 10, pp. 918-929, 2010.

[76] G. Schernthaner, E. Ritz, and G. H. Schernthaner, "Strict glycaemic control in diabetic patients with CKD or ESRD: beneficial or deadly?" Nephrology Dialysis Transplantation, vol. 25, no. 7, pp. 2044-2047, 2010.

[77] J. F. Mann, R. E. Schmieder, M. McQueen et al., "Renal outcomes with telmisartan, ramipril, or both, in people at high vascular risk (the ONTARGET study): a multicentre, randomised, double-blind, controlled trial," The Lancet, vol. 372, no. 9638, pp. 547-553, 2008.
[78] R. Agarwal, "Individualizing decision-making-resurrecting the doctor-patient relationship in the anemia debate," Clinical Journal of the American Society of Nephrology, vol. 5, no. 7, pp. 1340-1346, 2010.

[79] A. K. Singh, "ESAs in dialysis patients: are you a hedgehog or a fox?" Journal of the American Society of Nephrology, vol. 21, no. 4, pp. 543-546, 2010.

[80] E.V.O.L.V.E. Trial ${ }^{\mathrm{TM}}$, "EValuation Of Cinacalcet $\mathrm{HCl}$ Therapy to Lower CardioVascular Events," November 2010, http:// clinicaltrials.gov/ct2/show/NCT00345839.

[81] "Study of Heart and Renal Protection (SHARP)," November 2010, http://www.ctsu.ox.ac.uk/ sharp/.

[82] Kidney Disease Outcomes Quality Initiative (K/DOQI), "Clinical practice guidelines on hypertension and antihypertensive agents in chronic kidney disease," American Journal of Kidney Diseases, vol. 43, no. 5, supplement 1, pp. S1-S290, 2004.

[83] Kidney Disease Outcomes Quality Initiative (K/DOQI), “Clinical practice guidelines and clinical practice recommendations for diabetes and chronic kidney disease," American Journal of Kidney Diseases, vol. 49, no. 2, supplement 2, pp. S12-S154, 2007.

[84] A. Levin, B. Hemmelgarn, B. Culleton et al., "Guidelines for the management of chronic kidney disease," Canadian Medical Association Journal, vol. 179, no. 11, pp. 1154-1162, 2008.

[85] T. P. Peacock, Z. K. Shihabi, A. J. Bleyer et al., "Comparison of glycated albumin and hemoglobin A(1c) levels in diabetic subjects on hemodialysis," Kidney International, vol. 73, no. 9, pp. 1062-1068, 2008.

[86] B. C. H. Kwan, F. Kronenberg, S. Beddhu, and A. K. Cheung, "Lipoprotein metabolism and lipid management in chronic kidney disease," Journal of the American Society of Nephrology, vol. 18, no. 4, pp. 1246-1261, 2007.

[87] Kidney Disease Improving Global Outcomes (KDIGO), Clinical Practice Guideline for the Diagnosis, Evaluation, Prevention, and Treatment of Chronic Kidney Disease-Mineral and Bone Disorder (CKD-MBD), "Treatment of CKD-MBD targeted at lowering high serum phosphorus and maintaining serum calcium," Kidney International, vol. 76, supplement 113, pp. S50-S69, 2009.

[88] Kidney Disease Improving Global Outcomes (KDIGO) Clinical Practice Guideline for the Diagnosis, Evaluation, Prevention, and Treatment of Chronic Kidney Disease-Mineral and Bone Disorder (CKD-MBD), "Treatment of abnormal PTH levels in CKD-MBD," Kidney International, vol. 76, supplement 113, pp. S70-S89, 2009.

[89] R. Mehrota and R. Agarwal, "End stage renal disease and dialysis," NephSAP, vol. 7, no. 6, pp. 35-425, 2008.

[90] J. O. Burton, H. J. Jefferies, N. M. Selby, and C. W. McIntyre, "Hemodialysis-induced cardiac injury: determinants and associated outcomes," Clinical Journal of the American Society of Nephrology, vol. 4, no. 5, pp. 914-920, 2009. 


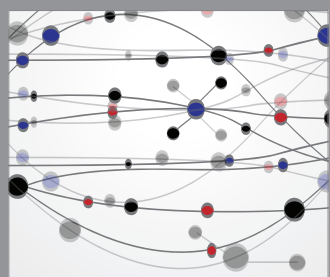

The Scientific World Journal
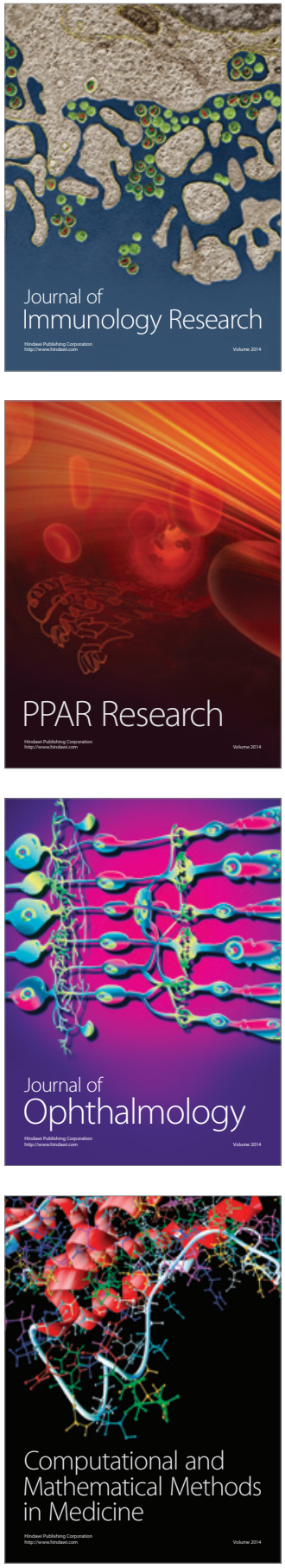

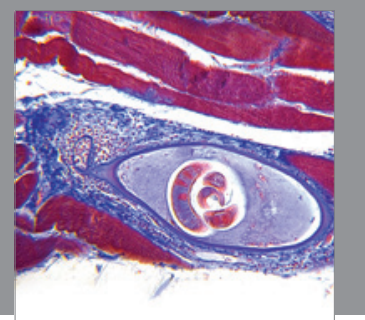

Gastroenterology

Research and Practice
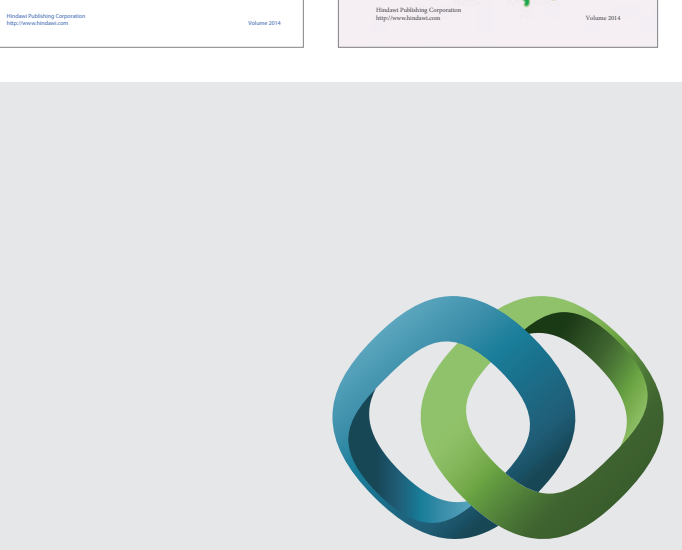

\section{Hindawi}

Submit your manuscripts at

http://www.hindawi.com
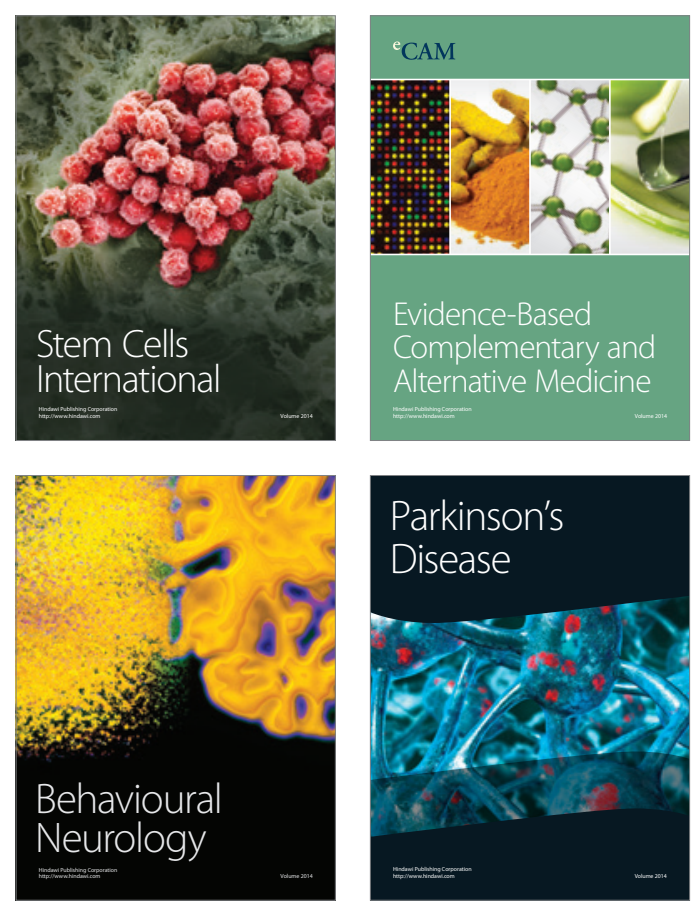

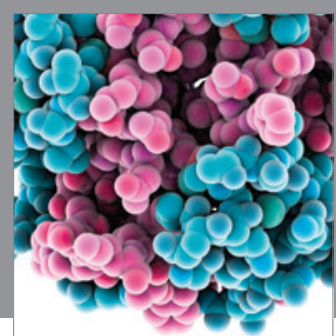

Journal of
Diabetes Research

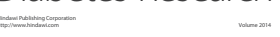

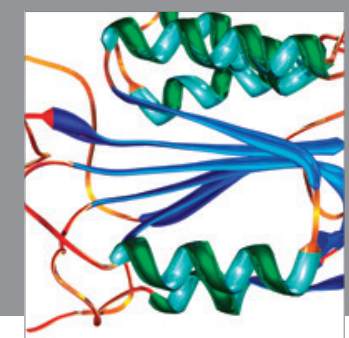

Disease Markers
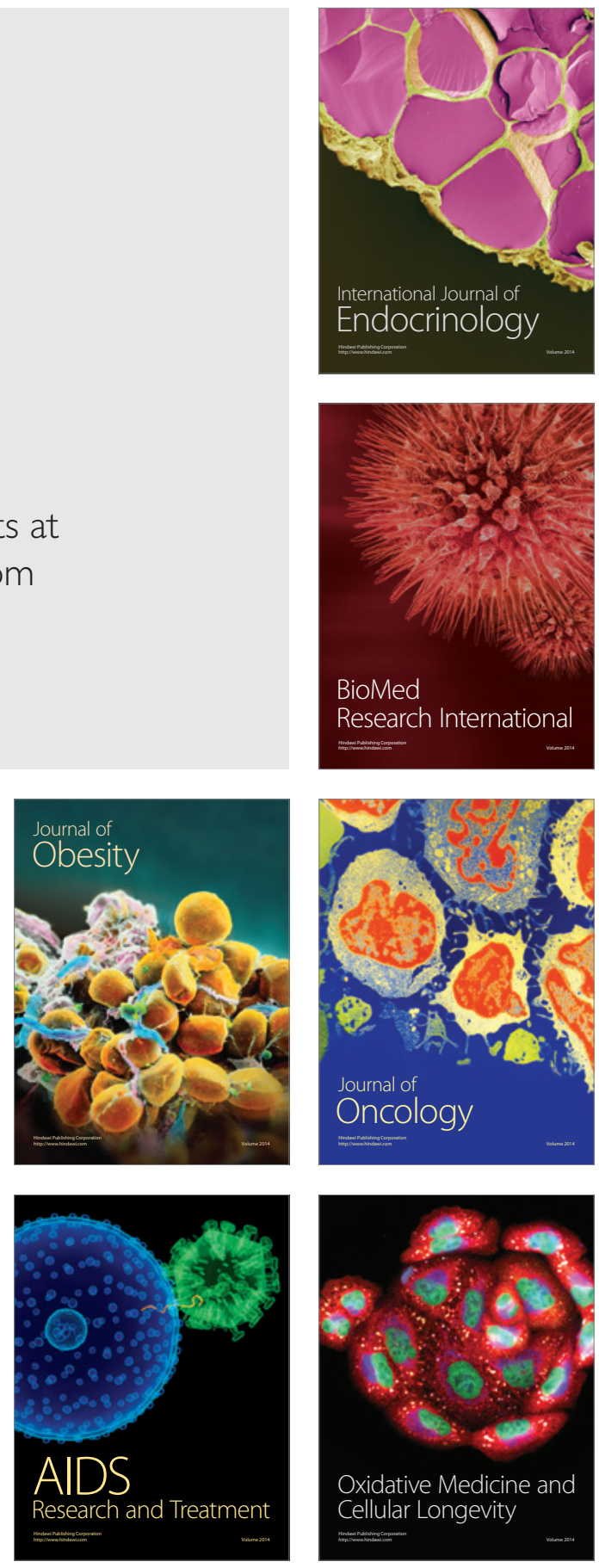